\title{
Creating a Culture of Wellness: A Call to Action for Higher Education, Igniting Change in Academic Institutions
}

\author{
Megan Amaya, PhD, CHES \\ The Ohio State University \\ Teresa Donegan, PhD \\ TDonegan Consulting, LLC \\ Debbie Conner, PhD, MSN, ANP/FNP-BC, FAANP \\ Franklin University \\ Julie Edwards, MHA \\ The University of Chicago \\ Christy Gipson, PhD, RN, CNE \\ The University of Texas at Tyler
}

\begin{abstract}
Background: Due to the continued rise of chronic conditions and unhealthy lifestyle choices, more innovative and evidence-based practices are needed for students, faculty and staff to improve population health outcomes and enhance overall well-being.

Aim: The purpose of this paper is to inform academic health promotion professionals of key strategies to consider in order to create cultures of wellness on their college campuses.

Methods: A review of the existing literature was conducted.

Results: The most current evidence-based practices to create a culture of wellness are discussed.

Conclusions: Institutions of higher education have an opportunity to create campus cultures that foster health and well-being. The time is now for enacting change to create, improve, or sustain cultures of wellness within campus communities.
\end{abstract}

Submitted 4 September 2019: accepted 27 September 2019

Keywords: culture of wellness, universities, health promotion, well-being

We are currently at a critical moment in the health and wellness of Americans. Six in ten adults in the United States have a chronic disease; four in ten have two or more (Centers for Disease Control and Prevention [CDC], 2019). Obesity has surpassed tobacco as the number one cause of preventable death and disease in the United States (Cleveland Clinic, 2017). The rate of mental health conditions is increasing among college students, with top diagnoses being anxiety, depression and panic attacks (Oswalt et al., 2018). Suicide is now the second leading cause of death in the United States among college students (CDC, 2017). Suicide rates have increased by $30 \%$ in nearly every state from 1999 through 2016 (CDC, 2019). Conversely, seventy-five percent of chronic conditions are preventable. Key lifestyle 
risks include tobacco use, unhealthy food choices and portion control, inactivity, excessive alcohol use and unmanaged stress (CDC, 2019).

In the field of worksite health promotion, historically, corporations have been the leaders in instituting workplace wellness programs. One of the aims of such programs is to reduce health care costs (Kent, Goetzel, Roemer, Prasad, \& Freundlich, 2016). Employers have also become increasingly more interested in other benefits of wellness programs, including employee recruitment, retention, work engagement, productivity and business outcomes, such as customer satisfaction. Based on recent Gallup data (Gallup, 2018), only 34\% of American workers are engaged in their work. In other words, a minority of employees are passionate about what they do. Fifty-three percent are slightly or not engaged, and 13\% are actively disengaged, acting out their dissatisfaction at the workplace (Harter, 2018). In the corporate world, employers with their focus on innovation and progress rely on the talent of their employees to think critically and originally to solve problems and create solutions. Lack of engagement can cripple an organization's ability to grow and thrive.

At the inaugural Building Healthy Academic Communities National Summit April 2013, renowned keynote speaker from the Johnson \& Johnson's Human Performance Institute, Jack Groppel, PhD, presented a new paradigm that linked work performance to level of engagement (Groppel, 2013). Groppel suggested underutilized human assets can lead to tens or hundreds of millions of dollars in lost productivity. Lack of engagement can lead to high turnover rates. Organizations may try to improve performance by offering training and professional development opportunities; however, increasing work demands and rapid technological and social changes result in employee stress and take a toll on their personal lives (Groppel, 2016).

\section{WELLNESS INITIATIVES IN HIGHER EDUCATION}

In large part, throughout the history of academic institutional wellness programming, wellness programs have typically been geared for the student population. Most institutions and executive administrators are challenged with sustaining themselves financially, by remaining competitive in the marketplace, and attracting and retaining students. Executive leadership, faculty and staff are becoming more aware of the impediments that undermine student success metrics, like sleeplessness, anxiety, stress, depression, poor eating habits, lack of activity and overall poor coping mechanisms (American College Health Association, 2018). Although many academic institutions have instituted wellness programs for students and/or employees, there are a limited number who have implemented comprehensive, structured and integrated approaches to health and wellness (Hill-Mey et al., 2015). At the 2015 International Conference on Health Promoting Universities and Colleges, the Okanagan Charter (2015), an international organization based in Canada, presented a "transformative vision for health promoting universities and colleges." The Charter provides a rationale for the need to develop cultures of wellness at universities, positing that higher education plays a central role in all aspects of the development of individuals, communities, societies and cultures - locally and globally. Academic institutions have a unique opportunity and responsibility to provide transformative education, engage the student voice, develop new knowledge and understanding, lead by example, and advocate to decision-makers for the benefit of society. In the emergent knowledge society, higher education institutions are positioned to generate, share and implement knowledge and research findings to enhance the health of citizens and communities both now and in the future. The sheer volume of people who live, work and visit academic institutions can allow for a greater collective impact, with work done collaboratively in transdisciplinary and cross-sector ways. Higher education institutions can 
incorporate health promotion values and principles into their mission, vision and strategic plans, and model and test approaches for the wider community and society. While the charter provides a framework for embedding health into all aspects of campus culture, it does not yet provide specific examples of what has been successful in creating a culture of wellness at academic institutions.

As of 2016, fifty-seven percent of colleges and universities reported offering an employee wellness program (College and University Professional Association for Human Resources, 2017). Published research (Madison, 2016; Jones, Molitor, \& Reif, 2018; Song \& Baicker, 2019) on the subject have touted wellness programs as ways to enhance morale, boost productivity, reduce turnover, lower healthcare costs, and improve overall population health (Health Enhancement Research Organization, 2015). In 2015, in a study conducted by Harrill, Lawton, and Fabianke, the investigators found that the core component of student success was based on faculty and staff engagement. The study results recognized that the key to successful, sustainable and impactful organizational and cultural change hinged on faculty and staff. They should not only be engaged but should lead or "drive" the work (Harrill, Lawton, \& Fabianke, 2015).

According to Gallup (Marken \& Matson, 2019), faculty and staff who are emotionally and psychologically engaged are more committed to their work and produce better student outcomes than less-engaged peers. Based on their research, only $34 \%$ of faculty and staff within higher education are engaged at work, which is lower than those in industry settings. Challenges include over ambitiousness and hastiness in taking on too many initiatives at one time, poor project planning, or taking on projects that do not fit the needs and culture of the institution. Top-down leadership can also lead faculty and staff to feel that their input and expertise are not valued. Higher education needs to continue to make the case for creating a culture of wellness that will benefit all of society, starting locally on our college campuses, to improve population health and decrease fiscal strain on our healthcare system.

The National Consortium for Building Healthy Academic Communities was created to harness the brainpower of academic institutions to address the impending healthcare crisis. When academic institutions take the lead in creating best practices and standards in health and wellness, they support the health efforts of their own students, faculty, and staff, as well as facilitate wellness in the surrounding community. The spirit of the Consortium is collaborative in nature. One of its goals is to promote transdisciplinary wellness partnerships, education and initiatives across academic institutions. Participating institutions can benefit from both sharing innovative initiatives and learning from others' successes. This "call to action" paper is targeted at institutions that are in the initial discussion or strategic planning phases of creating a culture of wellness, regardless of size or resources. The purpose of this paper is to provide strategic guidance gleaned from lessons learned from the corporate sector as well as several academic institutions that have fully implemented a comprehensive wellness initiative. The hope is to inspire change, while considering that plans will have to be tailored to be both feasible and manageable.

\section{DEFINITIONS, KEY CONCEPTS, AND ELEMENTS FOR CONSIDERATION}

When considering health and wellness initiatives, a good place to start is to identify how these elements have been defined by corporate, academic and government entities. The prevailing nomenclature used across the U.S., particularly in healthcare and health promotion contexts, is a "culture of health." The Robert Wood Johnson Foundation (RWJF, 2019), an organization at the forefront of creating a culture of health from a broad community perspective, identifies four action areas in their model: (1) making health a shared value; (2) fostering cross-sector 
collaboration to improve well-being; (3) creating healthier, more equitable communities; and 4) strengthening integration of health services and systems. According to RWJF, a culture of health seeks healthier communities, promotes the integration of systems to create healthier choices for all, now and for generations to come, and includes shared values, and collaboration (RWJF, 2019).

Healthy Campus 2020, a component of the American College Health Association (ACHA, 2018), supports the ecological model for all academic wellness programming. The social ecological theory considers the various contexts that influence how individual choices are made including whether to adopt healthy behaviors and to participate in wellness programming (Terrell, 2015). The ecological theory was created to move away from overemphasizing individual choice in decision making around health behavior. When health promotion and disease prevention gained interest in private, public and professional sectors in the late sixties, critics accused proponents of life-style interventions of fostering victim-blaming ideology and neglecting the significance of social influences on health and disease (McLeroy, Bibeau, Steckler, \& Glanz, 1988). The ecological model focuses attention on both individual and social environmental factors as targets for health promotion endeavors. The social ecological theory identifies five levels of influence on behavior:

- Intrapersonal: The individual's own set of characteristics, such as knowledge, attitudes, behavior, self-concept, skills;

- Interpersonal: Formal and informal social network and support systems which can include, but is not limited to, family, work groups, and friendship networks;

- Institutional: Social institutions with organizational characteristics and formal and informal rules and regulations for operation;

- Community factors: Relationships among organizations, institutions and informal networks within defined boundaries; and

- Public policy: Local, state, and national laws and policies.

For example, assuming an employee is "motivated to participate (intrapersonal), with supportive co-workers, and has a worksite which offers time off to participate (institutional), that worker will be more likely to participate than if only one or two of these influences are present" (Linnan et al., 2001). Several organizations have included ecological theory in their definitions of what constitutes a culture of health:

- A workplace ecology in which the dynamic relationship between human beings and their work environment nurtures personal and organizational values that support the achievement of a person's best self while generating exceptional business performance (Pronk, 2010);

- a workplace ecology that is intentionally designed with elements that support health and well-being (Health Enhancement Research Organization [HERO], 2016);

- and workplace wellness programs that involve "a coordinated, systematic and comprehensive set of strategies which include health programs, policies, benefits, environmental supports and links to the surrounding community designed to meet the health and safety needs of employees (CDC, 2016)."

In summary, an ecological model focuses on population- and individual- level determinants of health and interventions. It acknowledges that health is influenced by an array of interdependent factors including community, institutional, interpersonal, and intrapersonal components (ACHA, 2018). 
The World Health Organization (WHO) originally defined health as a "state of complete physical, mental, and social wellness, and not merely the absence of disease or infirmity" and a fundamental human right without distinction of race, religion, political belief, economic or social condition (WHO, 1946; WHO, 2006). Current definitions attempt to embody a variety of components that contribute to health. The shift from "health" to "wellness" nomenclature was derived to acknowledge that being healthy is no longer predicated on the physical dimension alone. The Substance Abuse and Mental Health Services Administration (SAMHSA) suggested eight dimensions of wellness including physical, intellectual, environmental, financial, occupational, social, emotional, and spiritual dimensions (SAMHSA, 2016).

When applied to wellness, health promotion practitioners need to consider how a program supports the individual, impacts the population, aligns with health promoting policies, and has a positive influence on the organization's culture and environment. It must also synergize with the mission and goals of the organization.

\section{ASSESSMENT OF IMPACT}

There has been a small amount of evidence published on the topic of return on investment (ROI) and value on investment (VOI). A study on ROI published by Goetzel et al. (2014), demonstrated a range of $\$ 2$ - $\$ 10$ return on investment for every $\$ 1$ spent on health and wellness. The settings for the research included private and corporate organizations, so generalizability is limited; however, it provides important evidence for health promotion leaders as they make the business case to top level leaders at their institutions. Value on investment is a more recent concept to the field. VOI refers to a wider range of metrics including but not limited to: Engagement, productivity, resilience, and the ability to attract and retain talent (employees and students). While it often pertains more to employee attributes and experiences, it may also be applicable to student populations. The "student experience," a metric of notable consideration in the student services and higher education world, helps attract and retain students. High quality student programming can include health and wellness opportunities to enhance the undergraduate and graduate experience and improve academic performance (Ruthig, Marrone, Hladkyj, \& Robinson-Epp, 2011). In addition, students take those health-promoting skills and strategies with them into their professional and personal lives once they graduate.

\section{PRIVACY ISSUES AND GAINING BUY-IN}

Kristen Madison (2016) offers an analysis and commentary in her article "The risks of using workplace wellness programs to foster a culture of health." She argues that employers, motivated by the potential for financial gains related to health improvement may create substantial risks. She raises the following concerns: Employees may end up shouldering more of the health costs, there is an increased possibility in employment discrimination, and finally there is the potential for employers' invasion of employees' privacy. If faculty and staff perceive that their institution's primary motivation for introducing wellness initiatives is the bottom line, they may feel coerced into participating. They may also worry that their employers are tapping into their personal health records through insurance claim data.

Goetzel, et al. (2017) responded to Dr. Madison's commentary and agreed that there is a problem with singlefocused wellness programs that are based on the premise that incentivizing employees to improve their health is all that is needed to create a healthy workforce. They argue that the actual problem however has to do with poor design and believe that programs that focus solely on providing financial incentives for achieving targeted health outcomes 
can result in unintended consequences as mentioned above. The authors posit that workplace wellness programs that are founded on a strong culture of health can influence employees' health and well-being in a practical, ethical and legal way. They further state that while it is the purview of employers to select which outcomes they focus on, research has shown that the foundational difference between effective and ineffective programs is their intervention focus. Finally, they noted that most companies are moving away from traditional ROI models to ones that value VOI metrics and they believe it is "the right way to go" (Goetzel, et al., 2017).

\section{KEY BEST PRACTICE STRATEGIES}

A culture that promotes wellness requires an array of key components in order to flourish. These factors include but are not limited to:

1) A systemic approach with a shared vision, mission and framework to guide strategy;

2) Leadership and management support, which includes verbally supportive messaging about why the institution invests in wellness, role modeling healthy behaviors, and allowing for wellness activities to take place during the workday;

3) Policies and procedures that support wellness. For example, a tobacco-free campus;

4) Access to outcomes data and evaluation of the culture, initiative and programming on a regular and consistent basis;

5) Resource allocation and commitment, such as financial funding, dedicated staff and physical space/prompts;

6) Grassroots efforts and peer support, such as student and faculty/staff wellness champion teams;

7) Partnerships and collaborations between groups within and outside the institution to further the cause;

8) Practices that are based on evidence using well-defined metrics of success that also allow for innovation and creativity to interweave when appropriate;

9) Effective communication about wellness opportunities and resources;

10) A sense of community in which people participate in programs and services;

11) Meaningful incentives that encourage participation; and

12) On-boarding and orientation to the initiative, along with annual training and learning opportunities;

13) Involving and obtaining feedback from students and/or faculty and staff in the design and implementation of programs;

14) Rewards and recognition for students, faculty and staff;

15) A variety of options that appeal to different interests.

These important considerations and best practices should be included in any comprehensive and integrative wellness initiative, addressing students and faculty/staff concerns. Understandably, not all institutions are to the point where they can implement all of the strategies recommended above. The health promoting practitioner needs to understand what elements can be implemented to create a culture of wellness and begin the process of discovering and delivering what is appropriate for their current environment. A first step could be conducting a needs assessment for all members of the institution's community. Organizational wellness programs operate on a continuum and need to start somewhere. Targeting practices that are most realistic and feasible to implement first, while working on the potentially more challenging aspects over time, make sense logically and can prove to be winnable outcomes to help pave the way for more advanced practices. It takes many years to change culture, to see notable VOI, and for certain 
practices to unfold. The "low hanging fruit," however, can produce results in a more reasonable time frame. Additionally, it will be key to measure and track progress for what is implemented. Accountability and quality improvement will provide you the means to acquire additional resources and support.

\section{UNIVERSITIES WHO ARE WALKING THE WALK}

This section briefly showcases several institutions of higher learning who are implementing a culture of wellness on their college campuses. Each one uses a foundation and strategy to drive programming and engagement. They all utilize multiple best practices noted previously. Although this is not an exhaustive list, it is encouraging that more and more universities and colleges are adopting a framework that incorporates students, faculty and staff; and additionally in most cases, visitors and guests to their college campuses.

Binghamton University's Healthy Campus Initiative (HCI), B-Healthy, is based on an eight-dimension model of wellness that supports the vital components of learning, living and working within a community whose vision is to become a premier public university for innovation in campus and community health and well-being (J.M. Fioreconte, personal communication, June 5,2019). The HCI's ecological approach illustrates the interconnectedness of the many aspects of living and how, together, they contribute to a healthy existence and offer a multi-faceted view of the connections between health, learning, productivity and campus structure. Population and individual action items and objectives are data-driven and tied directly to the priorities of the university president's Road Map to Premier strategic plan. Collaborations with key partners and multiple constituents have proven to be fundamental in moving the HCI forward.

Case Western Reserve University has utilized the culture of health guidelines established by the Wellness Council of America (WELCOA) to develop their wellness program. The seven benchmarks of success include: (1) capturing senior-level support; (2) creating cohesive wellness teams; (3) collecting data to drive health efforts; (4) crafting an annual operating plan; (5) choosing appropriate interventions; (6) creating a supportive, health-promoting environment; and, (7) measuring and evaluating program outcomes (Click, 2017). The initiative focuses on creating a campus environment that supports the health and wellness of faculty and staff to maximize their quality of life and productivity and to help control health care costs. An incentivized program is available to all benefits-eligible faculty and staff. The program incorporates evidence-based strategies into all programs and services to maximize impact and to facilitate lifestyle behavior changes within the population. A Wellness Champions network, workplace integration strategies, and community-building efforts have been particularly effective in enhancing well-being on campus. Over the past five years, increasing numbers of faculty and staff have participated in the worksite wellness program with $64 \%$ meeting the entry requirements in 2018. Data analysis and evaluation occurs regularly to monitor outcomes.

In 2017, the university launched a student wellness initiative. It includes a variety of programs to help foster wellbeing within the student population. Each semester, both wellness teams collaborate to offer a comprehensive program for all faculty, staff and students at the university. Keys to success within the programs include emphasis on policy modifications and environmental change and support in addition to lifestyle behavior change programs, and participation behavior change challenges. Utilizing a multi-pronged approach ensures full well-being integration for those who work, study, and live on campus (E.R. Click, personal communication, June 12, 2019).

Duke created the "Duke Healthy Campus" in 2016 as part of the Healthy Campus 2020 Initiative that aims to engage the Duke community to build a healthy organization where faculty, staff and students "thrive and feel valued." 
(Healthy Duke, n.d.) Spearheaded by Chancellor Eugene Washington in 2016, he engaged leaders from across the institution to see how they could harness the collective impact of people, programs and strategies to create a framework for this process. They developed a strategy around five focus areas: Food and nutrition, mental and emotional wellbeing, physical activity and movement, fulfillment and purpose, and environment and culture. Leaders from across the Duke community are facilitating working groups for each of the five key focal areas with a goal of fostering inclusiveness, connectivity and innovation that fosters the health and wellness of all in their community. The initiative is overseen by a steering committee composed of the key leaders of the institution (i.e., Chancellor of Health Affairs, Vice President of Administration, Vice President of Student Affairs, Chief Human Resources Officer for Duke University Health System).

"Live for Life," Duke's employee wellness program, offers a variety of programs and services including health assessments and education, smoking cessation programs, and fitness and nutrition activities. "Duwell" is Duke's student-centered initiative that helps students focus on their individual wellness by looking at the integration of many facets (i.e., intellectual, environmental, mind-body, financial, identity, values, choices, spiritual) of their life through wellness promotion and risk mitigation. Through the provision of a variety of wellness experiences they aim to help students manage stress and reduce anxiety while emphasizing self-care. Their comprehensive education framework addresses topics like sexual health, alcohol, tobacco and other drugs and how they impact student life to help students identify risky behaviors as part of their risk mitigation strategy. All programs are geared toward fostering daily practices of health and wellbeing (T. Szigethy, personal communication, June 11, 2019).

The Georgia Institute of Technology (Georgia Tech) acknowledges that it is a diverse and complex environment that strives for high levels of achievement where our community members seek to balance the personal and professional challenges that are a part of life (S. Connell, personal communication, June 12, 2019). Georgia Tech believes wellbeing is an essential piece of the human condition. Wellbeing is the fluid state of life satisfaction impacted by circumstances, environment, and culture. Georgia Tech prepares and equips its community members with the fundamental tools and life skills to thrive. Health and wellbeing at Georgia Tech (HW@GT) unites Campus Recreation, Counseling Center, Health Initiatives, Stamps Health Services and the newest department CARE, the Center for Assessment, Referral and Education, cultivate a culture of health, wellbeing, and resilience through promoting and delivering programs, services, and experiences with compassion and strategic collaboration. Under joint leadership from the Division of Student Life and Division of Campus Services, HW@GT envisions students, faculty, and staff will lead balanced, connected, and purposeful lives where they experience high levels of physical, emotional, social, and professional wellbeing.

Illinois State University has been creating a culture of wellness since 1984 when President Lloyd Watkins established the Faculty Staff Wellness Initiative (N. Brauer, personal communication, June 20, 2019). Implemented under the guidance of an interdisciplinary Wellness Committee, the team applied best practices from the beginning. Key drivers are the Wellness Ambassador Program and the creation of the Wellness Participation Policy allowing employees up to 90 minutes per week to engage in health and well-being programs, events, and services, and a partnership with the Academic Areas in what is known today as The School of Kinesiology and Recreation. After 35 years, these initiatives remain strong and steady.

In 2009, health promotion and wellness for faculty, staff and students were brought under one roof, as a standalone department to further the mission of Advancing Wellness at All Levels. By addressing well-being at the population level, engaging the entire campus community in the health promotion process became a reality. The work 
is built on the socio-ecological framework and the eight-dimension model. Evidence shows that collaborative work is the heart of advancing well-being across a community and is practiced through diverse initiatives. In 2017, the health and wellness Community of Practice was established in the Division of Student Affairs. Now reporting to the Vice President for Student Affairs are Campus Recreation, Health Promotion and Wellness, Student Counseling Services, and Student Health Services; they are charged with being an educational partner elevating well-being for all who live, learn, and work at Illinois State. The Community of Practice departments are involved in numerous partnerships across campus and together they are involved and leading the Jed Campus Program, Exercise as Medicine on Campus, the first cohort of the Culture of Respect Collective through NASPA, and in April 2019 joined the Partnership for a Healthier America Healthy Campus program.

Commitment from the highest levels is demonstrated through the university strategic plan, Educate-ConnectElevate Illinois State, where goals committing to further community well-being are placed to strengthen and enable a thriving body of students, staff, and faculty.

North Carolina State University has created a multifaceted wellness strategy which serves as the institution's approach for university wellness initiatives (Wolfpack Wellness, n.d.). It is derived from foundational frameworks of the socioecological model of health promotion, common language from the Gallup-Purdue text Wellbeing and concepts from Simon Sinek's It Starts With Why. The model, referred to as "Build a Thriving Pack" examines people, places and culture. The initiative includes (1) leadership support, (2) marketing and communications, (3) health promotion policy, (4) built environment, (5) peer support, (6) built environment, (7) responsibility and (8) a sense of community.

The Ohio State University has a comprehensive and integrative approach to the One University Health and Wellness initiative. Fostering a collaborative nature, the initiative is built upon the social-ecological framework and nine dimensions of wellness. A wellness council, under the leadership of a university chief wellness officer, oversees and directs strategic vision, including communication, leadership and management support, resource allocation, and partnerships; and evaluates key program outcomes from a scorecard that measures wellness culture, population health and fiscal spending. Robust, wellness champion teams exist for students and faculty/staff (Amaya, Melnyk, Buffington, \& Battista, 2017), and practices, resources, and programs are based on evidence.

The University of $\mathbf{U} \operatorname{tah}(\mathbf{U}$ of $\mathbf{U}$ ) is establishing a culture of wellness using a collective impact approach with multiple collaborative partners (R. Marcus, personal communication, June 17, 2019). The appointment of a Chief Wellness Officer (CWO) for University of Utah Health in 2015 created opportunities for streamlining existing wellness initiatives, and strategically aligning the creation of new programs. Comprehensive wellness services for students continue to be offered across campus with the Campus Counseling Center, Student Life Center, Center for Student Wellness, and Undergraduate Medical Education Wellness Program. A robust Graduate Medical Education Wellness Program was established in 2016. Under the leadership of the CWO and with an interprofessional advisory group, U of U Health launched the Resiliency Center in 2017 to promote faculty and staff wellness through advocacy, collaboration and innovative programming focused on individual and system resilience. Under the leadership of the CWO, Wellness and Integrative Health now offers faculty and staff Resiliency Center services as well as fitness and nutrition services, the National Diabetes Prevention Program, Tobacco Cessation, and Mindfulness Based Stress Reduction. With a grant from the American Cancer Society's Tobacco Free Generation Campus Initiative, the University became 100\% tobacco free in 2018. University leadership support 
has been strong with the University joining the Partnership for a Healthier America's Healthy Campus Initiative in 2019 and the establishment of a campus-wide Wellness Committee.

\section{LESSONS LEARNED AND IMPLICATIONS}

Much of the published research for employee wellness program outcomes comes from industry, specifically the corporate setting. Traditionally, academic institutions have lagged behind corporations for a host of reasons: Funding constraints, state-run insurance programs, complex research processes, gaps in translational research, and transient populations, particularly among students, which can be problematic for long-term follow-up. The American College Health Association conducted a survey in 2014 to assess the current state of faculty and staff health and wellness programs. In the survey, a question asking which resources would be most helpful for implementing employee wellness programs was included, and 39\% of respondents answered "best practices." When asked about barriers to program success, the top three barriers identified were cost of offering the program, lack of staff resources, and lack of time of participants (Almeda, Brauer, Dewald, \& Yingling, 2014). While more research and sharing of outcomes and best practices is needed in settings of higher learning, health promotion professionals need to create solutions to the multiple barriers inhibiting their ability to offer effective programming. Partnerships and collaborations can prove to be very beneficial, bringing together teams and people across campus (e.g., facilities, transportation, human resources, student wellness, health sciences colleges) who can help implement strategies and accomplish goals together.

\section{CONCLUSION: CALL TO ACTION}

It is clear that the need for effective change and action is warranted. First, universities must understand that every person impacts the well-being of the campus community. Bringing together people representing all campus sectors to share a common agenda and collaborate on wellness initiatives is crucial to effective change. By working together to implement changes at the policy, institution, interpersonal and individual levels, collective impact can happen to improve the well-being of students, staff and faculty. We urge universities to consider these strategies to improve or sustain their culture of wellness. The time is now. 


\section{REFERENCES}

Almeda, J., Brauer, N., Dewald, L., \& Yingling, F. (2014). The current state of faculty and staff health and wellness programs: Results from 2014 ACHA survey. Retrieved from https://www.acha.org/documents/resources/survey_data/Faculty_Staff_Health_Wellness_Programs_2014 _Survey_Results.pdf

Amaya, M., Melnyk, B., Buffington, B., \& Battista, L. (2017). Workplace wellness champions: Lessons learned and implications for future programming. Building Healtby Academic Communities Journal, 1(1), 59-67. https://doi.org/10.18061/bhac.v1i1.5744

American College of Health Association (ACHA; 2018). Healthy Campus 2020 Ecological Model. Retrieved from https://www.acha.org/HealthyCampus/HealthyCampus/Ecological_Model.aspx

American College of Health Association (ACHA; 2018). National College Health Assessment II Fall 2018. https://www.acha.org/documents/ncha/NCHA-II_Fall_2018_Reference_Group_Executive_Summary.pdf

Center for Disease Control and Prevention (CDC; 2017). WISQARS. Leading Cause of Death Reports 2017. Retrieved from https://webappa.cdc.gov/sasweb/ncipc/leadcause.html

Center for Disease Control and Prevention (CDC; 2019). National Center for Chronic Disease Prevention and Health Promotion. Chronic Diseases in America. Retrieved from https://www.cdc.gov/chronicdisease/resources/infographic/chronic-diseases.htm

Centers for Disease Control and Prevention (CDC; 2019). Suicide rising across the US. https://www.cdc.gov/vitalsigns/suicide/

Cleveland Clinic. (2017, April 22). Newsroom. Cleveland clinic study finds obesity as top cause of preventable life-years lost. [Press release]. Retrieved from https://newsroom.clevelandclinic.org/2017/04/22/cleveland-clinic-studyfinds-obesity-top-cause-preventable-life-years-lost/

Click, E.R. (2017). Creating a culture of health - One university's experience. In. A. Frame (Content Ed.) Health Matrix: Journal of Law-Medicine, 27, 417-434.

College and University Professional Association for Human Resources (2017). Benefits in Higher Education Survey. A transformative vision for health promoting universities and colleges. https://www.cupahr.org/surveys/results/benefitsin-higher-education/2017/ Accessed March 11, 2019

Gallup (2018). Employee Engagement on Rise in U.S. https://news.gallup.com/poll/241649/employeeengagement-rise.aspx. Accessed June 8, 2019.

Goetzel, R., Henke, R., Tabrizi, M., Pelletier, K., Poeppke, R., Ballard, D., .. Metz, R. (2014). Do workplace health promotion (wellness) programs work? Journal of Occupational Environmental Medicine, 56(9), 927-934. https://doi.org/10.1097/JOM.0000000000000276

Goetzel, R., Roemer, E., Henke, R., Kent, K., Berko, J., \& McCleary, K. (2017, January 23). Building a culture of workplace health: More complicated than offering workers money to be healthy. [Blog]. Retrieved from https:/ /www.healthaffairs.org/do/10.1377/hblog20170123.058414/full/ 
Groppel, J. (2013). The biology of business performance in academia: a business case for individual and organizational health. Presented at the Inaugural Building Healthy Academic Communities National Summit, Columbus, OH.

Groppel, J. (2016). Does your organization have a human energy crisis? Johnson \& Johnson Human Performance Institute. Retrieved from https://globalleadership.org/articles/leading-yourself/organization-humanenergy-crisis-jack-groppel/

Harrill, M., Lawton, J., \& Fabianke, J. (2015) Faculty and staff engagement: A core component of student success. Association of American Colleges \& Universities. Retrieved from https://www.aacu.org/peerreview/2015/fall/harrill

Harter, J. (2018). Employee Engagement on the rise in the U.S. Gallup. Retrieved from https://news.gallup.com/poll/241649/employee-engagement-rise.aspx.

Health Enhancement Research Organization (2015). Exploring the value proposition for workforce health. Retrieved from https://hero-health.org/wp-content/uploads/2015/02/HPP-Business-Leader-Survey-FullReport_FINAL.pdf

Health Enhancement Research Organization (2016). Defining a culture of health: Key elements that influence employee health and well-being. Retrieved from https://hero-health.org/wpcontent/uploads/2016/09/CoH-Definition-and-Elements_final-v2.pdf

Healthy Duke. (n.d.) About. Retrieved from https://healthy.duke.edu/about/

Hill-Mey, P. E., Kumpfer, K. L., Merrill, R. M., Reel, J., Hyatt-Neville, B., \& Richardson, G. E. (2015). Worksite health promotion programs in college settings. Journal of Education and Health Promotion, 4, 12. https://doi.org/10.4103/2277-9531.154019

Jones, D., Moloiotr, D., \& Reif, J. (2018). What do workplace wellness programs do? Evidence from the Illinois Workplace Wellness study. National Bureau of Economic Research. https://doi.org/10.3386/w24229

Kent, K., Goetzel, R. Z., Roemer, E. C., Prasad, A., \& Freundlich, N. (2016). Promoting healthy workplaces by building cultures of health and applying strategic communications. Journal of Occupational and Environmental Medicine, 58(2), 114-122. https://doi.org/10.1097/JOM.0000000000000629

Linnan, L., Sorensen, G., Colditz, G., Klar, N., Emmons, K. (2001). Using theory to understand the multiple determinants of low participation in worksite health promotion programs. Health Education \& Behavior, 28(5), 591-607. https://doi.org/10.1177/109019810102800506

McLeroy, K., Bibeau, D, Steckler, A., \& Glanz, K. (1988) An ecological perspective on health promotion programs. Health Education and Behavior, 15(4), 351-377. https://doi.org/10.1177/109019818801500401

Madison, K. (2016). The risks of using workplace wellness programs to foster a culture of health. Health Affairs, 35(11). https://doi.org/10.1377/hlthaff.2016.0729

Marken, S., \& Maton, T. (2019) Why drive employee engagement in higher ed? Gallup. Retrieved from https://www.gallup.com/education/258344/why-drive-employee-engagement-higher.aspx 
Okanagan Charter: An international charter for health promoting universities and colleges (2015, June 22-25). Presented at the 2015 International Conference on Health Promoting Universities and Colleges/VII International Congress. Retrieved from https://internationalhealthycampuses2015.sites.olt.ubc.ca/files/2016/01/Okanagan-CharterJanuary13v2.pdf

Oswalt, S. B., Lederer, A. M., Chestnut-Steich, K. C., Day, C., Halbritter, A., \& Ortiz, D. (2018). Trends in college students' mental health diagnoses and utilization of services, 2009-2015. Journal of American College Health. https://doi.org/10.1080/07448481.2018.1515748

Pronk, N. (2010). A workplace culture of health. ACSM's Health \& Fitness Journal, 14, 6-38. https://doi.org/10.1249/FIT.0b013e3181d9f7b6

Robert Wood Johnson Foundation (2019). Building a culture of health. Retrieved from https://www.rwjf.org/en/cultureofhealth.html

Ruthig, J., Marrone, S., Hladkyj, S., \& Robinson-Epp, N. (2011). Changes in college student health: implications for academic performance. Journal of College Student Development, 52(3), 307-320.

https://doi.org/10.1353/csd.2011.0038

Song, Z., \& Baicker, K. (2019). Effect of a workplace wellness program on employee health and economic outcomes. Journal of the American Medical Association, 321(15), 1491-1501. https://doi.org/10.1001/jama.2019.3307

The Substance Abuse and Mental Health Services Administration (SAMSHA, 2016). Learn the eight dimensions of wellness. Retrieved from https://store.samhsa.gov/system/files/sma16-4953.pdf

Terrell, S. L. (2015). Using social ecological theory to determine worksite wellness programming barriers within a private midwestern higher education setting. The International Journal of Health, Wellness, and Society, 5(2), 31-43. https://doi.org/10.18848/2156-8960/CGP/v05i02/41122

Wolfpack Wellness (n.d.). Retrieved from https://wellness.ncsu.edu/

World Health Organization (WHO; 1946). Constitution of the World Health Organization as adopted by the international Health Conference, New York, NY. The Preamble of the Constitution of the World Health Organization, 80(12), 982.

World Health Organization (WHO; 2006). Constitution of the World Health Organization, Basil Documents, 45(S). https://www.who.int/governance/eb/who_constitution_en.pdf 
Author correspondence may be addressed to:

Megan Amaya, PhD, CHES

Assistant Professor

Ohio State University

1585 Neil Avenue

Columbus, Ohio 432190

amaya.13@osu.edu

\section{Author's Note and Acknowledgements}

The authors would like to thank colleagues from the universities cited in the paper, for contributing a description of their comprehensive wellness initiative at their respective university. 